\title{
Kajian Etnobotani Tumbuhan Dalam Upacara Kehamilan (Posipo) Hingga Masa Anak-Anak (Dole-Dole) Pada Masyarakat Wolio Kota Bau-Bau
}

\section{Study of Plant Ethnobotany in Pregnancy Ceremony (Posipo) Until Childhood (Dole-Dole) in Bau-Bau City Wolio Society}

\author{
Lili Darlian' ${ }^{1)}$ Damhuri $^{1)}$ Wa Ode Hasni ${ }^{1)}$ \\ ${ }^{1}$ Jurusan Pendidikan Biologi, FKIP, Universitas Halu Oleo Kendari
}

Received $2^{\text {th }}$ February $2019 /$ Accepted $28^{\text {th }}$ March 2019

\begin{abstract}
ABSTRAK
Tujuan dari penelitia ini adalah untuk mengetahui (1) jenis-jenis tumbuhan apa saja yang digunakan dalam upacara kehamilan (posipo) hingga upacara masa anak-anak (dole-dole), (2) organ apa saja yang dimanfaatkan dalam upacara kehamilan (posipo) hingga upacara masa anak-anak (dole-dole), (3) pemanfaatan tumbuhan yang digunakan dalam upacara adat kehamilan (posipo) hingga upacara masa anak-anak (dole-dole) oleh Masyarakat Wolio Kota Bau-Bau. Metode penelitian survey eksploratif dengan menggunakan teknik wawancara. Data yang diperoleh dianalisis secara deskriptif dengan mendeskripsikan ciri-ciri morfologi, organ yang dimanfaatkan serta mengidentifikasi dengan mengacu buku identifikasi. Berdasarkan hasil penelitian bahwa terdapat 24 jenis tumbuhan yang dimanfaatkan dalam upacara adat kehamilan (posipo), kelahiran (aqiqah) dan masa anak-anak (dole-dole). Jumlah tumbuhan terdiri dari 2 kelas, 12 ordo dan 13 famili. Kelas Dicotyledoneae sebanyak 8 jenis sedangkan Monocotyledoneae sebanyak 16 jenis. Berdasarkan hasil eksplorasi, keseluruhan tumbuhan yang ditemukan berasal dari pekarangan, perkebunan dan hutan. Famili terbanyak Arecaceae dan Liliaceae masing-masing 5 jenis dan Poaceae 3 jenis. Organ yang dimanfaatkan dalam upacara kehamilan (posipo) hingga masa anak-anak (doledole) adalah akar, rimpang, umbi, batang, daun, bunga, buah dan biji. Cara pemanfaatan tumbuhan dalam upacara beraneka ragam setiap prosesi, tata cara serta fungsi dan makna yang berbeda.
\end{abstract}

Kata Kunci : Etnobotani, Upacara Adat, Masyarakat Wolio

\begin{abstract}
This study investigated a natural acid-base indicator which is extracted from plants in Kupang city. There are 14 plants that potential as a source of natural indicator for acid base titration, i.e, Kol Ungu (Brassica oleracea Capitata Group), Turi Merah flower (Sesbania grandiflora L. Pers), Belimbing Wuluh flower (Averhoa bilimbi L), Kaktus
\end{abstract}

*Korespondensi:

email: lilidarlian fkip@uho.ac.id 
Merah fruit (Opuntia vulgaris Mill), Ruelia flower (Ruellia simplex), Flamboyan flower (Delonix regia), bugenvil flower (Bougainvillea spectabilis Willd.), Bayam Merah leaves (Amaranthus tricolor L.) Jamblang fruit (Syzygium cumini L.), Murbey fruit (Morus alba L.), Pinang fruit (Areca catechu L.), Sirih fruit (Piper betle L.), Kunyit (Curcuma longa Linn), and Nanas Kerang leaves (Rhoeo discolor). Plants extract shows a sharp color change in acid and base solution. Promising results as a natural indicator also shown in acid base titration which is have similar equivalent point to synthetic indicator. We can use these natural indicators as an alternative to synthetic indicator because they are found to be simple, very useful, cheap, easy to extract, accurate, and eco-friendly.

Keywords: plant, natural indicator, acid-base.

\section{PENDAHULUAN}

Masyarakat Indonesia dalam kehidupan sehari-hari memiliki budaya yang masih dominan akan unsur-unsur tradisional. Keadaan ini didukung oleh keanekaragaman hayati yang berasal dari berbagai ekosistem yang ada di Indonesia. Pemanfaatan keanekaragam hayati telah melalui sejarah panjang sebagai bagian dari kebudayaan (Rahyuni, Yniati, \& Pitopang, 2013).

Indonesia sebagai negara yang kaya akan suku budaya masyarakat juga kaya akan keanekaragaman jenis tumbuhan. Tumbuhan merupakan keanekragaman hayati yang selalu ada di sekitar kita, baik yang tumbuh liar ataupun yang sudah dibudidayakan. (Yuniati \& Alwi, 2010). Masyarakat tradisional telah lama memanfaatkan keanekaragaman hayati atau sumber daya alam yang ada di sekelilingnya (Sukmawati \& Yuniati, 2013). Karena kehidupan masyarakat tradisional yang sangat dekat dengan sumberdaya alam dan lingkungan, sehingga salah satu interaksi yang muncul berhubungan dengan pemanfaatan tumbuhan (Atok, Hikmat, \& Zuhud, 2010). Etnobotani adalah cabang keilmuan yang mempelajari hubungan langsung antara manusia dengan tumbuhan dalam hal pemanfaatan dan pengelolaannya terutama pada masyarakat tradisional (Atok et al., 2010).

Etnobotani memiliki potensi untuk mengungkapkan sistem pengetahuan tradisional suatu kelompok masyarakat atau etnis mengenai keanekaragaman sumberdaya hayati, konservasi dan budaya (Tapundu \& Anam, 2015)

Suku Buton memiliki adat istiadat yang beragam di beberapa wilayah di pulau Buton. Upacara adat sampai dewasa masih dilaksanakan sacara meluas di dalam masyarakat terutama masyarakat Wolio Kota Bau-Bau. Upacara adat masyarakat Wolio yang diwujudkan dalam upacara-upacara yang bersifat ritual diantaranya yaitu upacara adat kehamilan (posipo), kelahiran (aqiqah), dan masa anak-anak (dole-dole). Masyarakat Wolio masih mempertahankan adat istiadat yang sudah turun temurun sesuai dengan tradisi leluhurnya. Pada upacara kehamilan (posipo) hingga masa anak-anak (dole-dole) oleh masyarakat Wolio masih menggunakan tumbuhan serta selalu dilengkapi dengan masakan dan makanan khas dari Buton.

Pemanfaatan tumbuhan secara tradisional oleh masyarakat Wolio merupakan salah satu pengetahuan yang berkembang dan diwariskan secara turun temuran. Berkaitan dengan semakin bergesarnya pola hidup masyarakat tradisional ke modern, maka pengetahuan masyarakat Wolio dalam memanfaatkan beragaman jenis tumbuhan dalam pelaksanaan upacara yang bernuansa adat atau agama perlu digali agar pelestarian 
tumbuhan yang digunakan dalam kelengkapan upacara adat istiadat secara tradisional tetap terjaga.

Prance dalam Hoang et al (2008) menyatakan ada beberapa kategori pengunaan tumbuhan, yaitu: (1) Sebagai Makanan, berbagai jenis tumbuhan atau bagian tertentu dari tumbuhan untuk dikosumsi, seperti buah-buahan, kacang-kacangan, sayuran. (2) Bahan bangunan, sebagian besar jenis pohon digunakan kayunya sebagai bahan baku perumahan dan ornamen lainya dalam bagunan. (3) Produk rumah tangga, berbagai produk rumah tangga berasal dari tumbuhan seperti lilin, shampoo, sabun dan juga kerajinan tangan. (4) Obat-obatan, sangat banyak jenis obat-obatan yang digunakan berasal dari tumbuhan terutama untuk obat tradisonal. (5) Kayu Bakar. (6) Lainnya, seperti bahan baku kertas atau bubur kertas.

Beberapa jenis tumbuhan yang dimanfaatkan dalam upacara adat pada penelitian terdahulu, diantaranya daun sirih (Piper betle L) dalam upacara kehamilan (Cumpe) dan kelahiran (Sampua) (Wanulu, 2016), dalam upacara adat Barong Idher Bumi, Daur Hidup (kehamilan/kelahiran-perkawinan-kematian) (Pitopang, dkk. 2013), upacara adat Seblang dan Kebo-keboan, kamboja (Plumeria acuminate), mawar, melati, kenangan dan kantil (Karina, 2014) Bagian tanaman yang digunakan umumnya berupa daun, rimpang, buah dan bunga. Upacara Sipaha Lima menggunakan 17 jenis tumbuhan, yaitu: Kayu bintatar (Celtis rigescens), Aren (Arenga pinnata), sarung marnaek (Shorea spp), beringin (Ficus benjamina L), hautunggal (Cordyline sp), Silinjuang/hanjuang (Cordyline fruticosa), rondang merah (Hibiscus rosa-sinensis), bane-bane (Ocimum sp), pinang (Areca catechu), bambu (Bambusa sp), sirih (Piper betle), jeruk purut (Citrus hystrix), bangunbangun (Coleus amboinicus), timun (Cucumis sativus), pisang (Musa sp), beras (Oryza sativa), kemenyan (Styrax sumatrana) (Amrul dan Lubis, 2017).

Penelitian ini merupakan penelitian deskriptif dengan menginvetarisasi sejumlah tumbuhan yang digunakan dalam upacara kehamilan (posipo) hingga masa anak-anak (dole-dole) oleh masyarakat Wolio Kota Bau-Bau.

\section{METODE PENELITIAN}

Metode penelitian dilakukan dengan metode observasi dan wawancara secara mendalam (depth interview) serta menggunakan kuesioner. Wawancara ditujukan kepada ketua adat, lembaga adat dan masyarakat pengguna atau mengenal tentang pemanfaatan tumbuhan dalam upacara kehamilan (posipo) hingga masa anak-anak (dole-dole), dengan metode pengambilan sampel secara purposive sampling dan stratified random sampling (Singarimbun dan Effendi, 1995).

\section{Alat}

Alat perekam, kamera dan kuesioner (daftar pertanyaan dan panduan wawancara) yang telah disediakan terlebih dahulu.

\section{Bahan}

Spesimen tumbuhan yang diidentifikasi mengacu pada buku Flora karangan Steenis, CGGJ van (2013). 
Meliputi penetapan informan, wawancara, eksplorasi (penjelajahan), dokumentasi, koleksi tanaman (herbarium), identifikasi.

\section{Prosedur Kerja}

Tahapan Penelitian: (1) Mengumpulkan data jenis tumbuhan, (2) Data jenis tumbuhan diperoleh dengan melakukan wawancara dan pengisisan kuesioner dengan kepala adat, pemuka masyarakat dan masyarakat yang bisa memberi keterangan tentang pelaksanaan upacara dan jenis tumbuhan yang digunakan, peranannya dan sumber tumbuhan tersebut, (3) Mengumpulkan jenis tumbuhan yang diperoleh untuk dibuat herbarium guna dilakukan identifikasi dari jenis tumbuhan tersebut, (4) Melakukan identifikasi jenis tumbuhan, (5) Hasil identifikasi tersebut dilakukan pengelompokan dari jenis tumbuhan, (6) Melakukan analisis terhadap data yang telah diperoleh.

\section{HASIL PENELITIAN}

Berdasarkan hasil wawancara dengan informan, terdapat 24 jenis tumbuhan yang digunakan dalam upacara kehamilan (posipo) hingga masa anak-anak disajikan pada tabel 1 .

Tabel 1. Jenis-Jenis Tumbuhan yang Digunakan Dalam Upacara Kehamilan (posipo) Hingga Masa Anak-anak Masyarakat Wolio Kota Bau-Bau.

\begin{tabular}{|c|c|c|c|c|c|}
\hline \multirow[b]{2}{*}{ No } & \multicolumn{2}{|c|}{$\begin{array}{c}\text { Jenis Tumbuhan } \\
\end{array}$} & \multirow[b]{2}{*}{$\begin{array}{c}\text { Bagian yang } \\
\text { Digunakan }\end{array}$} & \multirow[b]{2}{*}{$\begin{array}{c}\text { Lokasi } \\
\text { Memperoleh } \\
\text { Tumbuhan }\end{array}$} & \multirow[b]{2}{*}{ Makna } \\
\hline & $\begin{array}{l}\text { Nama } \\
\text { Daerah } \\
\text { (Wolio) }\end{array}$ & Nama Latin & & & \\
\hline 1 & Kaluku & $\begin{array}{l}\text { Cocos nucifera var- } \\
\text { viridis }\end{array}$ & Buah & Kebun & $\begin{array}{l}\text { Kelak bayi tersebut } \\
\text { dapat berguna bagi } \\
\text { masyarakat }\end{array}$ \\
\hline 2 & Pangana & Areca catechu L. & Buah & Kebun & $\begin{array}{l}\text { Lambang kemuliaan } \\
\text { dan kesejahteraan }\end{array}$ \\
\hline 3 & Konau & Arenga pinnata Merr. & Buah & Kebun & $\begin{array}{l}\text { Persembahan kepada } \\
\text { Sang Pencipta dan } \\
\text { arwah para leluhur } \\
\text { serta } \\
\text { kekuatan }\end{array}$ \\
\hline 4 & Lauro bawine & Calamus zollingeri $\mathrm{B}$. & Daun & Hutan & $\begin{array}{l}\text { Persembahan kepada } \\
\text { Sang Pencipta dan } \\
\text { arwah para leluhur }\end{array}$ \\
\hline 5 & Kaladhi & Colocasia esculenta & Umbi & Pekarangan & $\begin{array}{l}\text { Persembahan kepada } \\
\text { Sang Pencipta dan } \\
\text { arwah para leluhur }\end{array}$ \\
\hline 6 & Kaowi-owi & Ipomoea batatas Linn. & Umbi & Kebun & $\begin{array}{l}\text { Persembahan kepada } \\
\text { Sang Pencipta dan } \\
\text { arwah para leluhur }\end{array}$ \\
\hline
\end{tabular}




\begin{tabular}{|c|c|c|c|c|c|}
\hline \multirow[b]{2}{*}{ No } & \multicolumn{2}{|c|}{ Jenis Tumbuhan } & \multirow[b]{2}{*}{$\begin{array}{l}\text { Bagian yang } \\
\text { Digunakan }\end{array}$} & \multirow[b]{2}{*}{$\begin{array}{c}\text { Lokasi } \\
\text { Memperoleh } \\
\text { Tumbuhan }\end{array}$} & \multirow[b]{2}{*}{ Makna } \\
\hline & $\begin{array}{c}\text { Nama } \\
\text { Daerah } \\
\text { (Wolio) }\end{array}$ & Nama Latin & & & \\
\hline 7 & Kamba lagi & Gomphrena globosa & Buah & Pekarangan & Melambangkan \\
\hline 8 & Tiwadha & $\begin{array}{l}\text { Artocarpus integra } \\
\text { Merr. }\end{array}$ & Batang & Pekarangan & $\begin{array}{l}\text { kekekalan } \\
\text { Penanda kehidupan } \\
\text { yang akan datang, } \\
\text { anak laki-laki kelak } \\
\text { menjadi pelaut dan } \\
\text { pekerja keras, bagi } \\
\text { anak perempuan akan } \\
\text { pandai memasak }\end{array}$ \\
\hline 9 & $\begin{array}{l}\text { Bawwa } \\
\text { maputhe }\end{array}$ & Allium sativum & Umbi & Pekarangan & $\begin{array}{l}\text { Persembahan kepada } \\
\text { Sang Pencipta dan } \\
\text { arwah para leluhur }\end{array}$ \\
\hline 10 & Nike & Cordlyne fruticosa $\mathrm{L}$. & Bunga & Pekarangan & $\begin{array}{l}\text { Melambangkan } \\
\text { warna hati agar anak } \\
\text { memiliki hati yang } \\
\text { baik dan bersih }\end{array}$ \\
\hline 11 & Campaka & $\begin{array}{l}\text { Plumeura acuminate } \\
\text { Ait. }\end{array}$ & Bunga & Pekarangan & $\begin{array}{l}\text { Melambangkan } \\
\text { kesungguhan }\end{array}$ \\
\hline 12 & $\begin{array}{l}\text { Kamba } \\
\text { wunara }\end{array}$ & $\begin{array}{l}\text { Caesalpinia } \\
\text { pulcherrima Swarts. }\end{array}$ & Bunga & Pekarangan & $\begin{array}{l}\text { Melambangkan } \\
\text { kekekalan }\end{array}$ \\
\hline 13 & Bawwa malei & Allium ascalonicum & Umbi & Pekarangan & $\begin{array}{l}\text { Persembahan kepada } \\
\text { Sang Pencipta dan } \\
\text { arwah para leluhur }\end{array}$ \\
\hline 14 & Loka & Musa paradisiaca $\mathrm{L}$. & $\begin{array}{l}\text { Daun } \\
\text { buah }\end{array}$ & Pekarangan & $\begin{array}{l}\text { Persembahan kepada } \\
\text { Sang Pencipta dan } \\
\text { arwah para leluhur } \\
\text { juga melambangkan } \\
\text { kehidupan yang baik }\end{array}$ \\
\hline 15 & Tawana Lapi & Hibiscus tiliaceus L. & Daun & Pekarangan & $\begin{array}{l}\text { Kekuatan dalam } \\
\text { kehidupan }\end{array}$ \\
\hline 16 & Libo & Ficus septica & Daun & Pekarangan & $\begin{array}{l}\text { Melambangkan } \\
\text { keselamatan }\end{array}$ \\
\hline 17 & Катьа три & Jasminum sambac Ait. & Bunga & Pekarangan & $\begin{array}{l}\text { Melambangkan } \\
\text { kesucian } \\
\text { kedewasaan }\end{array}$ \\
\hline 18 & Tangkurere & Averrhoa bilimbi & Buah & Pekarangan & $\begin{array}{l}\text { Persembahan kepada } \\
\text { Sang Pencipta dan } \\
\text { arwah para leluhur }\end{array}$ \\
\hline 19 & Panda & $\begin{array}{l}\text { Pandanus } \\
\text { amaryllifolius Roxb. }\end{array}$ & Daun & Pekarangan & $\begin{array}{l}\text { Persembahan kepada } \\
\text { Sang Pencipta dan } \\
\text { arwah para leluhur }\end{array}$ \\
\hline 20 & Thowu & $\begin{array}{l}\text { Saccharum } \\
\text { officinarum Linn. }\end{array}$ & Batang & Pekarangan & $\begin{array}{l}\text { Persembahan kepada } \\
\text { Sang Pencipta dan } \\
\text { arwah para leluhur }\end{array}$ \\
\hline
\end{tabular}




\begin{tabular}{|c|c|c|c|c|c|}
\hline \multirow[b]{2}{*}{ No } & \multicolumn{2}{|c|}{ Jenis Tumbuhan } & \multirow[b]{2}{*}{$\begin{array}{c}\text { Bagian yang } \\
\text { Digunakan }\end{array}$} & \multirow[b]{2}{*}{$\begin{array}{c}\text { Lokasi } \\
\text { Memperoleh } \\
\text { Tumbuhan }\end{array}$} & \multirow[b]{2}{*}{ Makna } \\
\hline & $\begin{array}{c}\text { Nama } \\
\text { Daerah } \\
\text { (Wolio) }\end{array}$ & Nama Latin & & & \\
\hline 21 & Bae & Oryza sativa $\mathrm{L}$. & Biji & Pekarangan & $\begin{array}{l}\text { Melambangkan } \\
\text { kesejahteraan }\end{array}$ \\
\hline 22 & Padamalala & Cymbopogen citrates & Batang & Pekarangan & $\begin{array}{l}\text { Persembahan kepada } \\
\text { Sang Pencipta dan } \\
\text { arwah para leluhur }\end{array}$ \\
\hline 23 & Gili & Piper betle Linn. & Daun & Pekarangan & $\begin{array}{l}\text { Melambangkan } \\
\text { kesejahteraan }\end{array}$ \\
\hline 24 & Mantomu & Curcuma domestica & Rimpang & Pekarangan & $\begin{array}{l}\text { Melambangkan } \\
\text { kecermelangan }\end{array}$ \\
\hline
\end{tabular}

\section{PEMBAHASAN}

Berdasarkan hasil penelitian diperoleh 24 jenis tumbuhan yang digunakan dalam upacara kehamilan (posipo) hingga masa anak-anak (dole-dole) masyarakat Wolio Kota Bau-Bau. Tumbuhan tersebut sebagian besar diperoleh dari pekarangan dan kebun. Masyarakat Wolio memanfaatkan tumbuhan tersebut dalam upacara kehamilan (posipo) hingga masa anak-anak (dole-dole) sebagai bahan masakan dan bahan pelengkap dalam upacara yang diletakkan dalam nampan besar untuk dibaca (haroa). Keberadaan tumbuhan ini diyakini sangat berpengaruh terhadap sakralnya upacara yang dilaksanakan. Hal ini sehubungan dengan makna yang dimiliki oleh setiap tumbuhan tersebut berbedabeda. Kelengkapan upacara ini masih dipertahankan sehingga jenis tumbuhan yang digunakan dalam upacara sengaja dibudidayakan dipekarangan maupun di kebun. Pengetahuan tentang tumbuhan yang digunakan dalam upacara kehamilan (posipo) hingga masa anak-anak (dole-dole), pada hakekatnya mempunyai nilai dan makna simbolis antara nilai religi, nilai pendidikan dan nilai moral dalam kehidupan masyarakat Wolio. Nilai-nilai tersebut dilestarikan sehingga upacara kehamilan (posipo) hingga masa anak-anak (dole-dole) tetap dilaksanakan.

Upacara kehamilan (posipo) merupakan upacara yang dilaksanakan bagi seorang calon ibu di kehamilan pertama, pada saat usia kandungan memasuki tujuh bulan. Tahapan pelaksanaannya meliputi: pencucian muka (Poperoua) dan pemberian makan (Pakandea). Poperoua (perou) dari bahasa Wolio berarti membasuh muka. Jadi poperoua merupakan upacara membasuh muka bagi ibu hamil dengan usia kandungan tujuh bulan. Pelaksanaan upacara pencucian muka (рореroua) dilakukan setelah magrib. Bahan dan kelengkapan yang diperlukan dalam upacara poperoua, diantaranya: air, kendi 2 buah, uang 2 sen dan kain putih sepanjang 2 meter (dapat diganti dengan sarung). Pada upacara ini, ibu hamil didudukkan di depan pintu menghadap kiblat dan didampingi oleh biisa (dukun). Pada ritual ini menggunakan kemenyan pada saat pembacaan doa. Kendi pertama yang berisi air dimandikan untuk ibu hamil kemudian dipecahkan sedangkan kendi yang kedua tidak tapi tetap disimpan. Hal ini bertujuan untuk menghilangkan sifat buruk pada ibu hamil, sedangkan kendi yang tidak dipecahkan melambangkan sifat-sifat yang baik pada ibu hamil. Selain itu penyimpanan kendi berisi air mengandung makna bahwa seseorang yanh hidup dibumi ini memounyai kedudukan dalam kehidupan bermasyarakat. 
Selanjutnya upacara pemberian makan (pakandea) yang berlangsung keesokan harinya. Upacara ini diawali dengan penyuapan nasi dan lauknya serperti telur, ikan, ayam dan manisan oleh dukun (biisa), kemudian disusul oleh ibu, mertua, serta keluarga lainnya. Hidangan yang disajikan pada upacara pemberian makan (pakandea) diletakkan pada nampan berisi nasi salarai (nasi diberi minyak), telur goreng, ikan, ayam, manisan, kue baruasa, onde-onde, kalo-kalo, waje, telur sinanga, buah pisang, dan ubi jalar goreng. Lauk pauk berupa ayam dan telur sinang dimasak menggunakan kelapa goreng yang disangrai dan ditumbuk halus hingga berminyak, serta dilengkapi bumbu halus seperti bawang merah (Allium ascalonicum), bawang puth (Allium sativum), batang sereh (Cymbopogon citrates) dan kunyit (Curcuma domestica). Manisan dibuat dari santan kelapa (Cocos nucifera) dan gula merah (Arenga pinnata Merr), sedangkan bahan campuran kue dari beras (Oryza sativa), gula merah (Arenga pinnata Merr), dan kelapa (Cocos nucifera). Pelaksanaan upacara pemberian makan (pakandea) ibu hamil menggunakan busana adat Buton (kombo). Dalam upacara ini, para penyuap/pemberi makan (posipo) memberikan hadiah kepada ibu hamil berupa uang (kasipo) yang berarti suapan yang diletakkan dipangkuan ibu hamil. Tujuan dari pelaksanaan upacara pakandea adalah agar ibu yang mengandung menjadi sehat dan kuat dalam menghadapi persalinan serta bayi yang dilahirkan juga sehat, tidak memiliki kekurangan dan memiliki sifat-sifat yang baik.

Setelah upacara pakandea selesai dan beberapa bulan kemudian tiba saatnya bagi ibu hamil akan melahirkan bayinya dengan bantuan dukun beranak (biisa). Bayi yang telah lahir dipotong ari-arinya oleh biisa, lalu dibersihkan kemudian dibungkus dengan daun libo (Ficus septica) yang melambangkan kehidupan sang bayi kelak dapat menjadi manusia yang lebih baik. Daun libo (Ficus septica) yang digunakan untuk bayi perempuan sebanyak 8 lembar sedangkan anak laki-laki 9 lembar. Bungkusan ari-ari dimasukkan ke dalam buah kelapa tua (Cocos nucifera) tanpa air. Setelah ari-ari dimasukkan dalam buah kelapa, sabuk kelapa dijahit dengan menggunakan rotan (Calamus zollingeri) lalu ditanam. Upacara selanjutnya adalah pemotongan rambut (akikah) yang menggunakan beberapa jenis tumbuhan sebagai kelengkapan ritual yaitu kelapa (Cocos nucifera) dengan tujuan agar kelak bayi tersebut dapat berguna bagi masyarakat yang diibaratkan semua bagian pohon kelapa memiliki manfaat, buah dan daun pisang (Musa paradisiaca) yang tumbuh tegak dan menghasilkan buah yang banyak, bunga melati (Jasminum sambac Ait) yang melambangkan kesucian serta kedewasaan, bunga kenop (Gomphrena globosa Linn) dan kamba manure (Caesalpinia pulcherrima Swartz) melambangkan kekekalan. Sekain itu terdapat beberapa perlengkapan lainnya seperti tanah dan kemenyan. Tanah dioleskan di bagian telapak kaki kanan dan kiri bayi setelah dibacakan doa oleh lebe (tokoh adat) dengan tujuan agar anak tidak mudah jatuh pada saat pertam kali menginjakkan kakinya di tanah atau saat mulai berjalan, sedangkan kemenyan lambang keabadian. Pengguntingan rambut diawali oleh tokoh adat (lebe), dilanjutkan dengan sanak keluarga secara bergiliran. Rambut yang digunting dimasukkan dalam buah kelapa (Cocos nucifera) yang sudah dilubangi. Tujuan upacara ini adalah agar kelak bayi tersebut menjadi anak yang taat beragama.

Upacara selanjutnya adalah dole-dole yang dilakukan pada masa anak-anak dengan tujuan agar terhindar dari segala macam penyakit. Pelaksanaan upacara dole-dole diawali dengan usapan (dipanimpa) oleh biisa dengan menggunakan dupa yang berasal dari kemenyan (Styrax benzoin L), pinang (Areca catechu), kunyit (Curcuma domestica), benang putih, kapur, rokok, telur dan daun sirih (Piper betle). Pelaksanaan upacara doledole dilengkapi dengan tiga buah kendi kuningan atau dari tanah liat dan sajian isi nampan 
untuk haroa (pembacaan doa). Ketiga kendi tersebut didalamnya berisi saba (ubi dan kelapa), pisang (Musa paradisiaca), ubi jalar (Ipomoea batatas Linn), dan batang lauro bawine (Calamus zollingeri). Adapun isi nampan untuk haroa berupa nasi puth (Oryza sativa), pisang (Musa paradisiaca), ubi jalar (Ipomoea batatas), Minyak kelapa (Cocos nucifera), lauk pauk (ikan bobara, ikan katamba, dan telur). Pengalas panci terbuat dari lauro bawine (Calamus zollingeri). Biisa mengusap anak dengan kemenyan agar anak tidak merasa kaget. Setelah diusap kemenyan, anak tersebut dilumuri minya kelapa (Cocos nucifera) di atas nampan yang alasnya dari daun pisang (Musa paradisiaca) dan dibacakan doa oleh biisa. Setelah didole-dole, anak dimandikan dengan air yang dicampur beberapa jenis tumbuhan diantaranya bunga campaka (Plumeria acuminate Ait), kamba manure (Caesalpinia pulcherrima Swartz), bunga melati (Jasminum sambac), puring, kenop (Gomphrena globosa), nike (Cordyline fruticosa L), benalu, benang putih dan cincin yang dimasukkan dalam loyang berisi air. Apabila salah satu jenis tumbuhan tidak ada maka biisa akan melengkapinya dengan doa.

\section{KESIMPULAN}

Terdapat 24 tumbuhan terinventarisir yang digunakan dalam upacara kehamilan (posipo) hingga anak-anak (dole-dole) pada masyarakat Wolio Kota Bau-Bau. Masyarakat Wolio memanfaatkan tumbuhan tersebut sebagai bahan kelengkapan dan masakan dalam upacara. Organ tumbuhan yang digunakan meliputi rimpang, umbi, batang, daun, bunga, buah dan biji dengan fungsi dan makna yang berbeda-beda.

\section{UCAPAN TERIMA KASIH}

Ucapan terima kasih disampaikan kepada Universitas Halu Oleo Kendari yang memfasilitasi penelitian ini.

\section{REFERENSI}

Amrul, H., M., Z, N., Lubis, N. (2017). Etnobotani Tumbuhan yang Digunakan Pada Upacara Sipaha Lima Masyarakat Parmalim. Prosiding SNaPP Sains dan Teknologi. 7 (2).

Hoang S. V, Pieter Baas dan Paul J. A. K. (2008). Uses and Conservation species in a National Park (Studi kasus of Ben En Vietnam). Jumal Economic Botany. Springerlink. Com.

Karina, S. (2014). Jenis Tumbuhan Berguna Pada Pekarangan Masyarakat Percampuran Di Kelurahan Layana Indah Kecamatan Palu Timur Sulawesi Tengah. Jurnal Biocelebes. 8 (2).

Rahyuni, Yniati, E., \& Pitopang, R. (2013). Kajian Etnobotani Tumbuhan Ritual Suku TAJIO di desa Kasimbar Kabupaten Paringi Mountong. Online Jurnal of Natural Science. 2(2).

Singarimbun dan Effendi. (1995). Metode Penelitian Survai. Jakarta: PT. Pustaka LP3ES. Yogyakarta. 
Steenis, CGGJ van. (2013). Flora, untuk sekolah di Indonesia. PT Balai Pustaka, Jakarta.

Sukmawati, N., \& Yuniati, E. (2013). Studi Etnobotani Tumbuhan Obat Pada Masyarakat Suku Kaili Rai di Desa Toga Kecamatan Ampibabo Kabupaten Parigi Moutong Sulawesi Tengah. Biocelebes. 7(2).

Tapundu, A. S., \& Anam, S. (2015). Studi Etnobotani Tumbuhan Obat Pada Suku Seko Di Desa Tanah Harapan, Kabupaten Sigi, Sulawesi Tengah. Biocelebes. 9(2).

Wanulu, R. (2016). Makna Interaksi Simbolik Pada Proses Upacara Adat Cumpe dan Sampua Suku Buton di Samarinda. Jurnal Ilmu Komunikasi. 4 (3).

Yuniati, E., \& Alwi, M. (2010). Etnobotani Keanekaragaman Jenis Tumbuhan Obat Tradisional Dari Hutan Di Desa Pakuli Kecamatan Gumbasa kabupaten Donggala, Sulawesi Tengah. Biocelebes. 4(1). 